LoutrT, J. S. (1958). J. gen. Microbiol. 18, 315-319

\title{
A Transduction-like Process within a Single Strain of Pseudomonas aeruginosa
}

\author{
By J. S. LOUTIT \\ Department of Microbiology, Medical School, University of Otago, \\ Dunedin, Nerv Zealand
}

SUMMARY: A process of genetic transfer, which could be demonstrated with culture filtrates of a strain of Pseudomonas aeruginosa, is described. The evidence indicates that genetic material was transferred in association with a large particle and that the process was similar to Salmonella transduction except that in the present case it occurred spontaneously between mutants of a single strain.

Three processes of genetic exchange have been demonstrated for bacteria. First, there was the process of pneumococcal transformation originally described by Alloway (1932). The active principle was shown to be a deoxyribonucleic acid by Avery, MacLeod \& McCarty (1944). Secondly, a sexual process was described by Lederberg \& Tatum (1946) for the K12 strain of Escherichia coli. Thirdly, Zinder \& Lederberg (1952) demonstrated genetic transfer by means of an infectious particle in the genus Salmonella.

Loutit (1955) reported a process of apparent genetic transfer which occurred in a strain of Pseudomonas aeruginosa during attempts to isolate auxotrophic mutants of that strain. Subsequently, Holloway (1955) reported a sexual recombination in $\boldsymbol{P}$. aeruginosa which occurred between different strains but not within the same strain. On further examination, Holloway (1956) reported that some of his strains were self-fertile, but he found no evidence of a filterable factor concerned either with the transfer process or with sexual compatibility. The present work is concerned with the process described by Loutit (1955), in an attempt to decide whether the process was sexual and if not, to decide whether it was a process of transformation, transduction or in fact a nonspecific mutagenic effect.

\section{METHODS}

Organisms. The wild-type strain B of Pseudomonas aeruginosa was isolated from a wound infection in Brisbane. The auxotrophic mutant organisms were some of those isolated by Loutit (1955) from strain B after ultraviolet irradiation. They were selected by a modification of the single-plate technique of Adelberg \& Myers (1953). The mutant strains used predominantly for this work were strains B17 ad- (adenineless) and B 21 ${ }^{1-}$ (leucineless).

\section{Media}

Complete medium. Nutrient broth was prepared from Bacto beef extract $3 \mathrm{~g}$. and Bacto peptone $5 \mathrm{~g}$. in $1000 \mathrm{ml}$. distilled water.

Minimal medium. The medium of Davis \& Mingioli (1950) was used, solidified with $1.5 \%(\mathrm{w} / \mathrm{v})$ washed agar. 
Preparation of cuture filtrates. Culture filtrates of the wild-type organism or of either of the mutant strains B $17^{\text {ad- }}$ and B $21^{1-}$ were obtained by growing these organisms in complete medium at $37^{\circ}$ overnight. The cultures were then centrifuged at $3000 \mathrm{rev} . / \mathrm{min}$. for $30 \mathrm{~min}$. in an angle-head centrifuge to remove most of the organisms and then the supernatant fluid was filtered through a sterile sintered glass filter (porosity $5 / 3$ ). At least $2 \mathrm{ml}$. of every filtrate was transferred aseptically to a sterile bottle and incubated at $37^{\circ}$ to test for the absence of living organisms.

Detection of filterable agent in culture filtrates. A just visible suspension of either mutant was prepared in sterile distilled water, and $0.5 \mathrm{ml}$. of it inoculated into $5 \mathrm{ml}$. sterile culture filtrate of strain B or the other mutant. At the same time the mutant was inoculated into $5 \mathrm{ml}$. sterile nutrient broth. The tubes were incubated overnight at $37^{\circ}$ and then the organisms were deposited by centrifugation at $2500 \mathrm{rev} . / \mathrm{min}$. for $20 \mathrm{~min}$. in an angle-head centrifuge. The organisms were washed twice in $10 \mathrm{ml}$. sterile distilled water and the organisms from both tubes finally suspended in $0.5 \mathrm{ml}$. vol. of sterile distilled water.

All the organisms grown in the nutrient broth were spread over the surface of two well-dried minimal agar plates. On the other hand, because of the possible large number of prototrophs in the organisms grown in the culture filtrates, $\mathbf{0} \cdot 1 \mathrm{ml}$. of the concentrate from the filtrate was spread over one welldried minimal agar plate and the remainder of the organisms in the concentrate were diluted $1 / 10$ and then $1 / 5$. Then $0.1 \mathrm{ml}$. from the $1 / 10$ dilution was spread over the surface of three minimal agar plates and the same procedure was carried out for the $1 / 50$ dilution. The spread plates were placed in the incubator at $37^{\circ}$ after the inoculum had dried on the surface and were then incubated and examined at 24 and $48 \mathrm{hr}$. for prototroph colonies.

\section{Nature of the filterable agent}

Action of deoxyribonuclease (DNase). The DNase was obtained from the Mann Research Laboratories, New York, and had been crystallized once. It was tested for activity on thymus deoxyribonucleic acid (DNA), using the viscosimetric methods of assay described by McCarty (1946). For the test on the culture filtrate, a solution containing $100 \mu \mathrm{g}$. DNase $/ \mathrm{ml}$. was prepared in $0.015 \mathrm{M}$-magnesium sulphate. Three ml. of this DNase solution was added to $12 \mathrm{ml}$. of a previously prepared culture filtrate of strain B giving a final concentration of $20 \mu \mathrm{g}$. DNase $/ \mathrm{ml}$. in $0.003 \mathrm{M}$-magnesium sulphate. The tube was incubated for $2 \mathrm{hr}$. at $37^{\circ}$ and then the contents were refiltered through a sterile sintered glass filter (porosity $5 / 3$ ) and $5 \mathrm{ml}$. of the filtrate was transferred to a sterile container. Control tubes were prepared by diluting $4 \mathrm{ml}$. of sterile nutrient broth and $4 \mathrm{ml}$. of the original culture filtrate with $1 \mathrm{ml}$. of sterile $0.015 \mathrm{M}-\mathrm{MgSO}_{4}$. All the tubes were then inoculated with $0.5 \mathrm{ml}$. of a suspension of strain $\mathrm{B}^{2} 1^{1-}$ in sterile distilled water. The tubes were incubated overnight at $37^{\circ}$ and the mutant cultures tested for the presence of prototrophs as described above.

Filtration through Gradocol membranes. A $20 \mathrm{ml}$. sample of a culture filtrate 
of strain B was prepared and $10 \mathrm{ml}$. filtered through each of two sterile Gradocol membranes. The membranes used had average pore diameters (A.P.D.) of 160 and $370 \mathrm{~m} \mu$., respectively. Five ml. samples of the filtrates were tested for the presence of a filterable agent after inoculation with strain $\mathbf{B} 2 \mathbf{1}^{1-}$. At least $2 \mathrm{ml}$. samples of these filtrates were used to check the sterility of the filtrate.

\section{RESULTS}

\section{Detection of a filterable agent}

Filtrates from the sintered funnels were always found to be sterile. If either mutant $\mathrm{B} 17^{\text {ad }}$ - or $\mathbf{B 2 1} 1^{1-}$ was inoculated and grown in such culture filtrates of strain $B$ and the mutant organisms were subsequently inoculated on to minimal agar plates, numerous small colonies appeared after $\mathbf{2 4} \mathrm{hr}$. incubation at $37^{\circ}$. These colonies were similar to the colonies of the wild-type organism (strain B). A similar result was obtained when one mutant was grown in the culture filtrates from other mutants. In contrast to this, virtually no colonies were seen on any of the control plates inoculated with all the organisms from $5 \mathrm{ml}$. of broth culture. An occasional colony was seen only once in several experiments. In several experiments, the mutants $\mathrm{B} 17^{\text {ad }}$ - and $\mathrm{B} 2 \mathbf{1}^{1-}$ were grown in filtrates prepared from strains $\mathrm{B} 17^{a d-}$ and $\mathrm{B} 21^{1-}$ respectively. In these experiments no prototrophs were detected.

When quantitative estimations were made of the number of prototrophs great variation was found in the numbers of prototrophs in different culture filtrates. The numbers varied between 500 and $30,000 / \mathrm{ml}$. of culture filtrate. The variation was not so great in replicate tests on the same culture filtrates but there was no correlation between the numbers. Variations from $3500 / \mathrm{ml}$. of culture filtrate to $9900 / \mathrm{ml}$. were demonstrated in the first experiment of Table 1. The figures could be used as an index of the amount of filterable agent only if absorption of the agent occurred at the end of the growth period. If absorption occurred at an earlier stage some of the prototrophs would undoubtedly be progeny of the organisms first treated. Since prediction of the time of absorption would be impossible the quantitative figures could not be used as an index of the amount of filterable agent but only as a qualitative test for the presence of the filterable agent.

\section{Nature of the filterable agent}

Action of DNase. The DNase at a concentration of $20 \mu \mathrm{g} . / \mathrm{ml}$. was shown to be an active depolymerase because it brought about a marked decrease in the viscosity of a solution of thymus DNA in $30 \mathrm{~min}$. at $37^{\circ}$. In tests on the culture filtrates the enzyme was used at $20 \mu \mathrm{g}$. $/ \mathrm{ml}$. for $2 \mathrm{hr}$., although other experiments, using higher concentrations of DNase and longer incubation times, were also carried out. In all these experiments there appeared to be no diminution in the amount of filterable agent as far as could be demonstrated by the number of prototrophs. There was no significant diminution in the number of prototrophs found in culture filtrates treated with DNase compared with that found in the untreated control filtrates. The number of prototrophs was always 
greater than $500 / \mathrm{ml}$. of culture filtrate. In some experiments the number in the treated filtrate was higher than that in the untreated filtrate while in others the number was lower.

Filtration through Gradocol membranes. The filtrates from the Gradocol membranes were always sterile. When a mutant was inoculated and grown in a culture filtrate from the $160 \mathrm{~m} \mu$. A.P.D. filter and the organisms were subsequently plated on minimal agar no prototrophic colonies appeared; but when inoculated and grown in the filtrate from the $370 \mathrm{~m} \mu$. A.P.D. filter prototrophic colonies appeared in large numbers. The results of two experiments have been set out in Table 1.

Table 1. Passage of filterable agent through Gradocol membranes demonstrated by the formation of prototrophs during groreth of Pseudomonas aeruginosa strain $B 21^{1-}$ in various culture filtrates of $\mathbf{P}$. aeruginosa strain $B$.

Growth medium

1. Nutrient broth control

2. Strain B filtrate from porosity $5 / 3$ sintered glass filter

3. Filtrate 2 refiltered through a $160 \mathrm{~m} \mu$. A.P.D. Gradocol filter

4. Filtrate 2 refiltered through a $370 \mathrm{~m} \mu$. A.P.D. Gradocol filter
No. of prototrophs/ml. of culture

$\begin{array}{rr}\text { Expt. 1 } & \text { Expt. } 2 \\ 0 & 0 \\ 3500 & 770 \\ 0 & 0 \\ 9900 & 1050\end{array}$

The results of these two experiments demonstrated the variability of the numbers of prototrophs found in different culture filtrates, as well as showing that the filterable agent was unable to pass through the $160 \mathrm{~m} \mu$. A.P.D. filter but passed through the $370 \mathrm{~m} \mu$. A.P.D. filter.

\section{DISCUSSION}

The results described indicate that the process described by Loutit (1955) within the strain B of Pseudomonas aeruginosa was not due to a sexual mechanism. There was no difficulty in demonstrating a filterable agent in sterile culture filtrates obtained from large surface area sintered glass filters (porosity 5/3). The U-tube technique described by Davis (1950) was not necessary.

The possibility that the agent was not a genetic transfer agent but was in fact a non-specific mutagenic agent was considered and then discarded since no prototrophs were demonstrated when mutants were grown in their own culture filtrates.

The results indicate that the process is a genetic transfer which is very closely allied to transduction demonstrated for the genus Salmonella. The filterable agent was not affected by deoxyribonuclease and seemed to be a relatively large particle. While Stocker, Zinder \& Lederberg (1953) stated that the genetic material transferred was probably the same in transformation and transduction, there does seem some point in distinguishing between these two 
processes, which have a different vector. In the present work it was certainly of interest to know whether some organisms naturally liberated deoxyribonucleic acid which was then taken up by other organisms and incorporated in them, or whether they liberated a particle which was capable of infecting other organisms.

Having established that there was a particle concerned it would be mere speculation at present to discuss the nature of the liberated particle. The only information available concerns the size of the particle; the results suggest that the particle might be as large as $100 \mathrm{~m} \mu$. in diameter. The phenomenon does seem to be sufficiently similar to Salmonella transduction to warrant the name of a transduction-like process and does provide additional interest in that transduction occurs spontaneously between organisms differing only in a single genetic characteristic. Zinder \& Lederberg (1952) demonstrated that the filterable agent obtained from Salmonella typhimurium strain LT-7 or different mutants of that strain could transduce other mutants of the same strain. Ho.. ever, the filterable agent for their work was not produced spontaneously but by an initial chemical treatment and inoculation of the filtrate obtained into broth containing the same strain of organisms. In the present work there appears to be a spontaneous liberation of the infectious particles in sufficient numbers not to require a lytic agent.

\section{REFERENCES}

Adelberg, E. A. \& Myers, J. W. (1953). Modification of the penicillin technique for the selection of auxotrophic bacteria. J. Bact. 65, 348 .

Alloway, J. L. (1932). The transformation in vitro of $R$ pneumococci into $S$ forms of different specific types by the use of filtered pneumococcus extracts. J. exp. Med. 55, 91.

Avery, O. T., MacLeod, C. M. \& McCarty, M. (1944). Studies on the chemical nature of the substance inducing transformation of pneumococcal types. Induction of transformation by a deoxyribonucleic acid fraction isolated from the pneumococcus type III. J. exp. Med. 79, 137.

Davis, B. D. (1950). Non-filtrability of the agents of genetic recombination in Escherichia coli. J. Bact. 60, 507.

Davis, B. D. \& Mingioli, E. S. (1950). Mutants of Escherichia coli requiring methionine or vitamin B12. J. Bact. 60, 17.

Holloway, B. W. (1955). Genetic recombination in Pseudomonas aeruginosa. J. gen Microbiol. 13, 572.

Holloway, B. W. (1956). Self-fertility in Pseudomonas aeruginosa. J.gen. Microbiol. $15,221$.

Lederberg, J. \& TAtum, E. L. (1946). Gene recombination in Escherichia coli. Nature, Lond. 158, 558.

Loutit, J. S. (1955). Auxotrophic mutants of Pseudomonas aeruginosa. Nature, Lond. 176, 74.

McCARTy, M. (1946). Purification and properties of desoxyribonuclease isolated from beef pancreas. J. gen. Physiol. 29, 123.

Stocker, B. A. D., Zinder, N. D. \& Lederherg, J. (1953). Transduction of flagellar characters in Salmonella. J. gen. Microbiol. 9, 410.

Zinder, N. D. \& Lederberg, J. (1952). Genetic exchange in Salmonella. J. Bact. 64,679 .

(Received 8 July 1957) 